\title{
El vestido y la cosmética en el Antiguo Egipto
}

\author{
Pilar González Serrano*
}

\begin{abstract}
En los tiempos actuales en los que el culto al cuerpo y al desnudo se impone con imágenes repetitivas, intentado derribar viejas barreras, es fácil de entender que el vestido no haya servido sólo para su abrigo y cubrición por decencia, como se solía decir en épocas más recatadas, sino que principalmente se haya utilizado para su adorno y realce.
\end{abstract}

Afortunadamente, la imaginación creativa del hombre es el motor genésico de los componentes más significativos de lo que entendemos por cultura. $Y$ lo cierto es que, de entre los muchos que la integran, merece destacarse el conjunto peculiar de las vestiduras y atuendos, de los tocados y adornos con los que los hombres de las distintas épocas de la Historia se han cubierto por necesidad y placer personal. Aparte de su vistosa utilidad, dicho conjunto ha sido y sigue siendo uno de los sistemas de comunicación más elocuentes de los generados hasta ahora. La simple observación de un atuendo proporciona una visión sintética de toda una realidad social, ya que a través del mismo se puede deducir no sólo el sexo de quien lo luce, la época y el país en el que vivió o vive su portador, sino también su condición social o religiosa, su profesión, oficio o cargo, sus gustos personales, etc.

Teniendo en cuenta que las formas del cuerpo humano son siempre las mismas, a pesar de las evidentes e inexorables diferencias que en ellas, por desgracia, marca el paso del tiempo, hay que reconocer que sólo cuando se alcanzan unos determinados niveles de cultura se puede sentir el placer de plasmar el gusto personal y la íntima forma de ser, a través del vestido $y$ de los adornos que se eligen para marcar la individualidad $y$

* Departamento de Arqueología. Universidad Complutense. 
diferencias con respecto a los demás. Por otro lado, el aspecto exterior logrado por añadidos supletorios sobre el animal desnudo que somos todos, acusa, incluso a pesar de la intención de quien los elige y luce, su íntima personalidad, para bien o para mal, traspasando sus propósitos subjetivos, evidenciando su forma de ser, su altivez o modestia, su petulancia, su buen o mal gusto, su carácter conservador o progresista, su equilibrio interior, etc. $Y$ esto, que sucede en el plano de lo individual, se repite y con más señales de peso y de identidad en el de lo nacional o regional, desde la más remota antigüedad hasta nuestros días. En las pinturas prehistóricas podemos comprobar que el cuerpo desnudo de un hombre o de una mujer, más o menos esquematizado, nada significa sino es una elemental diferenciación sexual, cuando ésta se manifiesta. Sin embargo un simple penacho de plumas sobre la cabeza de un individuo o un modesto birrete sobre una cabeza femenina emiten unos mensajes de jerarquía o de religiosidad que no se pueden ignorar, aunque se desconozcan sus auténticas claves.

En la actualidad, cuando las religiones oficiales y categorías tradicionales se van cayendo de las páginas de la Historia, como la ropa de los cuerpos jóvenes, el fenómeno de la comunicación de los atavíos sigue siendo, básicamente, el mismo, aunque de acuerdo con la nueva «sacralidad» generada en los santuarios de las grandes firmas que gobiernan el complejo mundo de la moda, desde donde se forman y exhiben a nuevos hierofantes y sacerdotisas, y desde donde se exigen implacables sacrificios de latría a sus adeptos y adeptas.

En el caso de Egipto, antes de pasar al estudio de sus vestidos y atuendos, hay que recordar que su clima uniforme, de carácter desértico, alcanza máximas de hasta $38^{\circ}$ en los meses de verano, sólo atemperadas en la zona mediterránea por influjo del mar, y que sus inviernos son muy suaves, con tan escasas precipitaciones que apenas si merecen consideración alguna. Por lo tanto, los egipcios pudieron y pueden ir siempre ligeros de ropa, de suerte que los vestidos y tocados que eligieron a través del tiempo más les han servido de adorno y protección de los rayos solares que de abrigo. El actual campesino egipcio viste una amplia y sencilla túnica («galabiyé»), prenda multiuso que le sirve en cualquier ocasión; y como ropa interior usa un amplio calzón, cuando lo lleva. El caso de la mujer egipcia actual es muy diferente, ya que se ve determinado por razones religiosas. En el camino de retroceso cultural marcado por el fundamentalismo islámico se la ha exigido perderse en la envoltura de mantos y velos que ya había comenzado a dejar atrás. 
En los tiempos prehistóricos, la desnudez debió de imperar en el seno de la mayoría de los clanes o grupos humanos que se asentaron en el valle del Nilo. De hecho, no debe olvidarse que la cultura egipcia es una cultura africana y que, por lo tanto, muchos de sus usos y costumbres aún pueden rastrearse entre los actuales nativos que habitan las regiones de Nubia y Etiopía. Las sucesivas dominaciones de pueblos extranjeros que ha sufrido el valle del Nilo y, sobre todo, a partir de la árabe en el siglo Ix de nuestra Era, han enmascarado sus auténticas raíces. De suerte, que aún resultan desconocidas para un gran número de egipcios, cuyo orgullo faraónico, subyacente bajo su religiosidad coránica, no pasa de ser un sentimiento difuso anclado en las moles de las pirámides que miles de turistas visitan cada año.

La Arqueología nos informa de que en los comienzos del Imperio Antiguo la desnudez era la apariencia con que los fieles debían presentarse ante la divinidad. Sin embargo, con el paso del tiempo, dicha desnudez pasó a convertirse en signo de baja condición social. Es muy posible que este cambio de postura se produjera al tiempo que en la esfera de las clases pudientes se generalizaba el uso de las vestiduras y atuendos como símbolos diferenciadores y de rango personal, elegidos por gusto y competitividad de realce frente a las clases trabajadoras e, incluso, frente a los enemigos, propios o extranjeros, a los que se enfrentaban. Por lo tanto, durante este período ya sólo se representaron desnudos a los niños, a los esclavos y a los prisioneros.

En virtud de esta exigida diferenciación social, una familia de alcurnia no permitía que las efigies de sus muertos aparecieran desnudas, por temor a que perdieran los signos de identidad propios de su casta y pudieran correr el riesgo de que los dioses los tomaran por gentes de baja condición. Debían, por lo tanto, presentarse en el «más allá» con sus mejores atavíos.

Con tales concepciones como punto de partida, habría que decir que vestirse en Egipto fue el arte de «ponerse» atuendos y tocados con el fin no sólo de adornarse, sino con el primordial de marcar el nivel social y estamental de cada individuo, bien definido, además, por las inscripciones en las que cada uno dejaba constancia de sus cargos y honores recibidos. En el caso del atuendo femenino, podrían aceptarse incluso los supuestos de la escuela freudiana que lo considera una potenciación del estímulo sexual. Como ejemplo ilustrativo procede recordar el pasaje del célebre cuento egipcio titulado "Historia de los dos hermanos", en el que una esposa al tratar de disculparse ante su marido por el adulterio que ha cometido con su cuñado utiliza el siguiente argumento: «me sorprendió 
cuando estaba sola, entonces me dijo: ven, pasemos una hora juntos, acostémonos. Ponte la peluca"...

A la hora de estudiar y de describir las vestiduras y tocados de los egipcios, al igual que sucede con otros pueblos de la antigüedad, lo primero que hay que tener en cuenta es que nuestras principales fuentes de información son las representaciones pictóricas que de ellas nos han llegado, ya que, aunque la sequedad del suelo nilótico ha permitido la conservación de algunos fragmentos textiles y vendajes de momias, no son más que vestigios dispersos que nos han ayudado a conocer la textura de sus más usuales tejidos. Con este panorama y dado que el arte egipcio es esencialmente de carácter religioso hay que tener presente que los ambientes reflejados en los relieves pictóricos de sus templos y tumbas corresponden a momentos puntuales y no siempre cotidianos. En consecuencia, muchos de los pliegues y tratamiento de los paños obedecen a razones más bien estéticas y convencionales que a las reales.

Los tejidos utilizados para la fabricación de los vestidos egipcios fueron los realizados con fibras vegetales. De entre ellos destacó el lino, afamado por su buena calidad, ya que reunía tres condiciones esenciales: ligereza, frescura y facilidad de lavado, cualidad esta última muy apreciada por los egipcios que consideraban a la limpieza como una parte integrante de la pureza. El color preferido era el blanco por razones de clima y por su significado sacro. Los tejidos de vivos colores se emplearon en mantos y chales, y el oro en los collares, alhajas y cinturones.

La lana se uitilizó, a veces, para prendas de abrigo, pero al parecer, considerada impura, no se permitía su uso en templos y tumbas. También hay quien sostiene que el hecho de que no haya restos de tejidos de lana en ninguna sepultura se debe a su rápida destrucción por la polilla y gusanos.

Los paños de lino se tejían en telares horizontales, documentados arqueológicamente desde el III milenio a.C. A partir del II milenio a.C. se utilizó también el vertical, como novedad tecnológica pero sin que llegara a suplantar al anterior, que fue siempre el más usado.

Las mejoras que se aprecian a finales del II milenio a.C. en la fabricación textil se asocian a las conquistas realizadas en Siria por Tutmosis III (1525-1512 a.C.), ya que el dominio de dicha región trajo como consecuencia la aparición de numerosos tejedores sirios en Egipto y el consecuente florecimiento de telares manejados por estos extranjeros que, 0 
bien llegaron al valle del Nilo como esclavos de guerra o atraídos por su situación de prosperidad política y económica. El caso es que el calificativo de "sirio" llegó a ser sinónimo de tejedor.

Como consecuencia de estas inmigraciones se introdujeron modelos de corte asiático, sobre todo en las capas altas de la sociedad, que sustituyeron a los tradicionales egipcios. Los influjos orientales, a partir de entonces, fueron constantes, intensificándose en la época ramesida (siglos XIII y XII a.C.) en la que triunfó el gusto por los tejidos transparentes y finamente plisados, así como por las mezclas de colores y tonos brillantes, produciéndose un fenómeno de refinado barroquismo que puede estudiarse especialmente en las representaciones pictóricas de las tumbas reales y de grandes dignatarios de las necrópolis tebanas.

\section{EL VESTIDO MASCULINO}

La pieza más simple y elemental de la indumentaria masculina fue la «shenti» (figuras 1 y 2 ), consistente en una tira de lino, estrecha y larga, que se disponía de modo que una de sus extremidades, doblada sobre sí misma sobre el vientre y sujeta por un cinturón, dejara una especie de lengüeta saliente por encima del mismo, pasara luego entre las piernas, se enrollase al cuerpo varias veces, para, por último, ajustarse bajo el ceñidor en la parte delantera, de forma sesgada y, por lo general, formando pliegues.

El uso de la túnica o «calasiris», se generalizó a partir de la segunda época tebana (1500-1090 a.C.) que fue cuando, como ya vimos, se dejaron sentir los influjos asiáticos y jonios en la indumentaria egipcia (figuras 3 y 4). Fue una prenda de lino transparente y de corte muy simple. Se componía de un largo trozo de tela, doblada por la mitad y abierto en su centro por un amplio escote por el que se introducía la cabeza. Sus extremos laterales iban cosidos, después de haber dejado libres dos largas aberturas que permitieran el paso de los brazos. Una vez puesta, se ceñía al talle con un cinturón. Fue una prenda de lujo, usada por personajes de alto nivel social y, en consecuencia, sometida a las veleidades de la moda. En caso de túnicas muy anchas, se disponían de manera que formaran, en la parte delantera, un delantal triangular surcado por finos pliegues, consecuencia probablemente de un engomado a base de engrudo de esta parte del tejido, tal y como vemos en muchas de la estatuas y representaciones pictóricas de esta época en las que la rigidez 


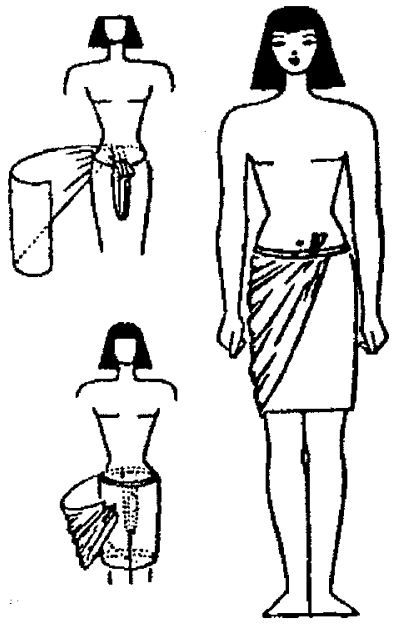

Figura 1. La «shenti» o calzón egipcio.

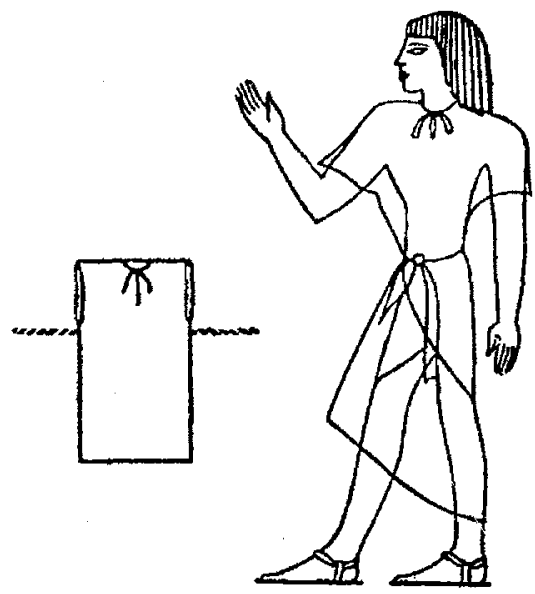

Figura 3. La "calasiris", túnica ceñida por un cíngulo o cordón a la cintura.

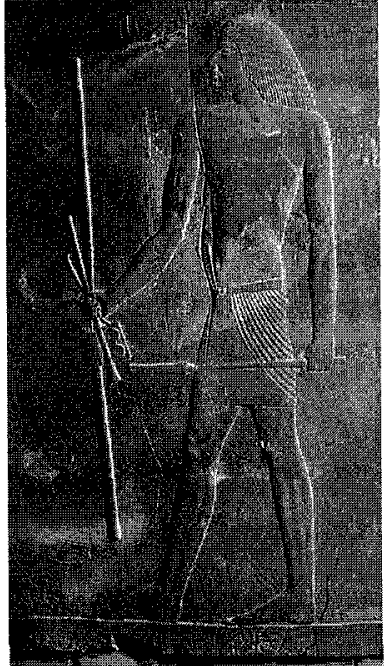

Figura 2. Hesiré, el "Prefecto de los Escribas del Rey" vistiendo la "shenti" Panel de madera (altura 1,14 m.) de su mastaba de Sakkará, dinastía III (hacia 2620 a.C.). Museo de El Cairo.

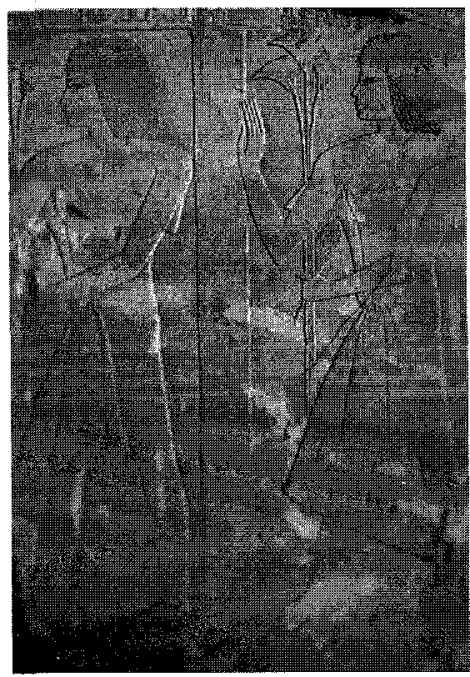

Figura 4. Relieves de la tumba de Ramose, visir de Amenofis III (1417-1379 a.C.) y Amenofis IV (1379-1362 a.C.). Familiares del difunto vistiendo la túnica transparente o "calasiris. Necrópolis tebana. 
del mencionado delantal triangular se ve acentuada de acuerdo con indiscutibles códigos estéticos.

El manto o «sush» (vocablo cuya en etimología contiene la idea de envolver) era la prenda que se arrollaba al cuerpo de la forma y manera que su usuario lo precisaba y deseaba (figura 5). También llamada «sindon» por influjo griego, podía enrollarse en la cintura, cubriendo caderas y piernas, o por debajo de las axilas (figura 6), formando, a veces, en la parte delantera un delantal triangular y, asimismo, engomado (figura 7). Sin embargo, según su disposición más usual, se ceñía a la cintura, y uno de sus extremos pasaba a cubrir el-hombro izquierdo, para caer sobre la espalda, dejando el brazo derecho al descubierto. En el Imperio Nuevo fue frecuente llevar sobre la "calasiris» el manto doblado envolviendo las caderas y anudado en la parte delantera (figuras 8 y 9 ).

\section{LA INDUMENTARIA REAL}

La indumentaria de los faraones fue básicamente igual a la de sus súbditos, pero enriquecida con atributos y adornos propios de la realeza. Durante el Imperio Antiguo sobre todo, la «shenti» fue también la prenda con que se hicieron representar los faraones y príncipes, aunque ceñida al talle por lujosos cinturones con pinjantes delanteros y traseros en los cuales se hacia figurar el nombre del personaje o sus insignias reales.

Vestidura propia del faraón fue también el «calambé real» (figuras $10 \mathrm{y}$ 11), faldellín finamente plisado o adornado con rayas horizontales azules, amarillas y verdes, separadas por estrechas franjas blancas. Su disposición era más complicada que la de la «shenti», pero se adaptaba al cuerpo de forma similar a la anterior, contando como punto de sujeción con un cinturón o cíngulo. Sobre el vientre y sujeto por el cinturón se dejaba suelto un largo trozo de uno de los extremos del paño. El resto del mismo se pasaba entre las piernas y se sujetaba en la parte posterior bajo el cinturón. El extremo suelto se arrollaba entonces alrededor de las caderas y se sujetaba, de nuevo, en el centro de la cintura tras pasar su extremo por debajo del cíngulo. Era frecuente que otro cinturón exterior, de lujo y con adornos colgantes, ciñera el «calambé real». a menudo pende de su parte trasera un simbólico rabo de toro, como ya se aprecia en la famosa Paletá del rey Namer (hacia el 3000 a.C.). 

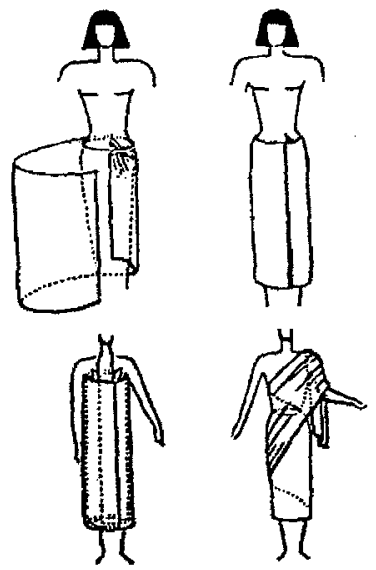

Figura 5. El manto o "sush", también llamado "sindon" por los griegos.

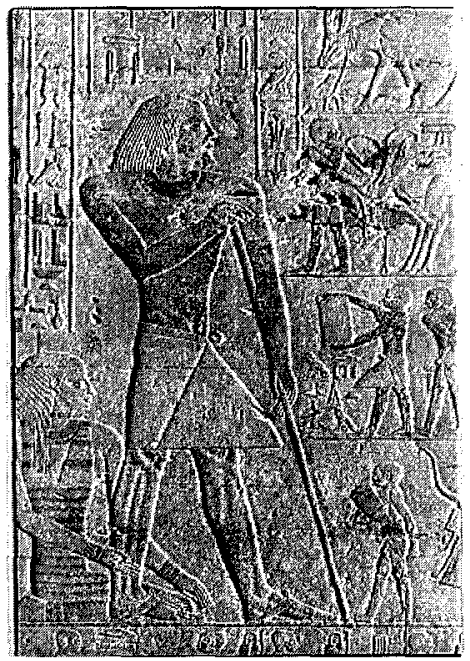

Figura 7. Ti, vistiendo manto corto arrollado a la cintura, ligeras sandalias, peluca corta y barba postiza, y su mujer Neferhetepes, con túnica ceñida al cuerpo y larga peluca. Tumba de $T i$, alto funcionario de Niuserre (2453-2422 a.C.), faraón de la dinastía $V$, en Sakkará.

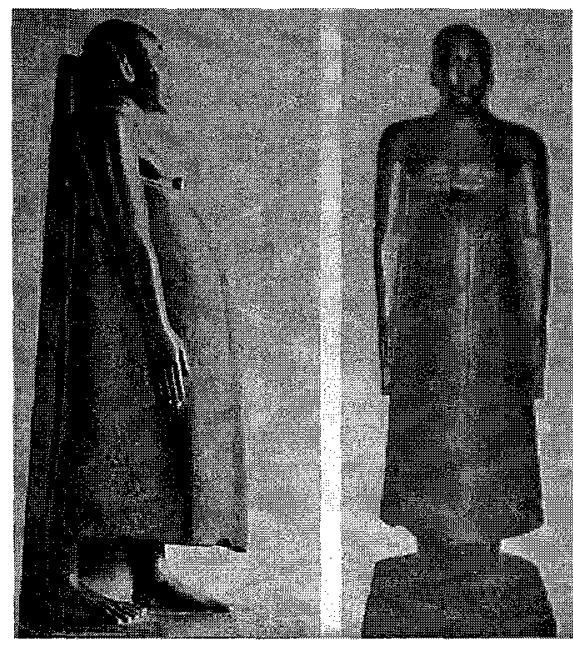

Figura 6. Sebekemsuf, hermano de una de las reinas de la dinastía XII (1001-1777 a.C.), vistiendo un manto colocado debajo de las axilas.

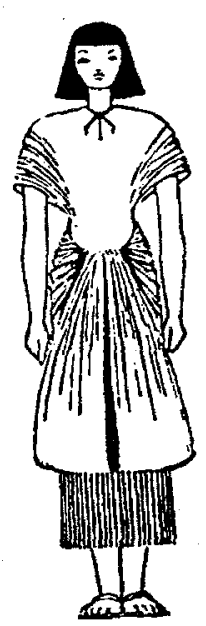

Figura 8. "Calasiris" plisada $y$ «shush» envolviendo las caderas y anudado en la parte delantera. 


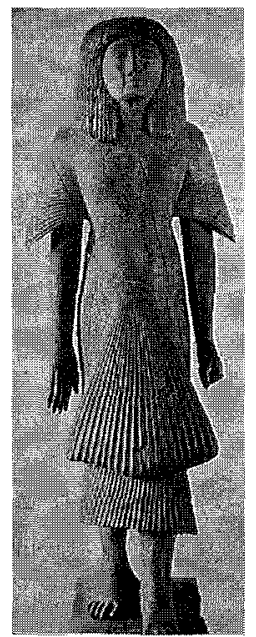

Figura 9. Piai, uno de los superintendentes de las obras de Amenofis III (1417-1379 a.C.), vistiendo «calasiris" plisada y «sush" envolviendo las caderas y anudado en la parte delantera.

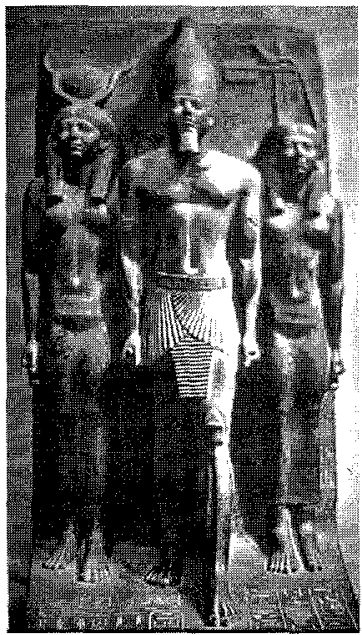

Figura 11. Micerinos, faraón de la dinastía IV (2528-2500 a.C.), vistiendo el «calambé real" y luciendo el "hedyet» o tiara blanca del Alto Egipto, acompañado de la diosa Hathor y de la diosa de Kynópolis. Relieve procedente del templo del valle de su pirámide de Giza (92,5 cm. de altura). Museo de El Cairo.
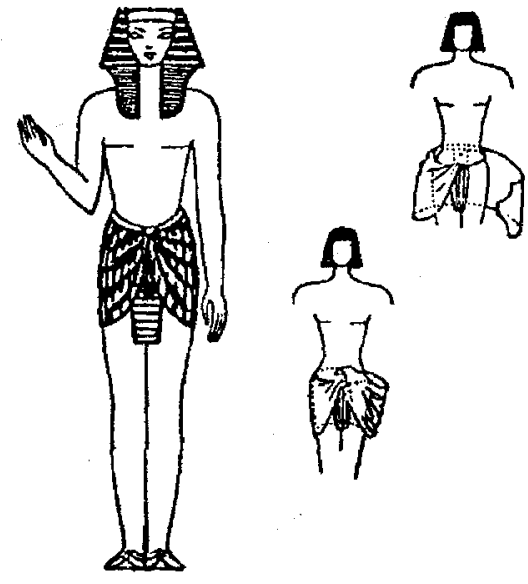

Figura 10. El «calambé real», prenda que vestian habitualmente los faraones.

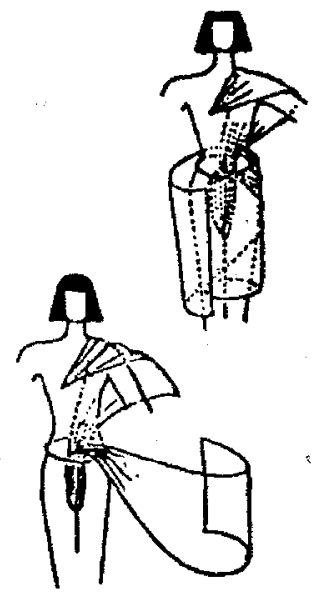

Figura 12, La llamada "vestidura colgante". 
Un antecedente de esta prenda quieren verla algunos investigadores en la llamada "vestidura colgante» de época predinástica (hacia 3200 a.C), porque servía a la vez de "calambé» y de túnica (figura 12). El largo trozo de tejido partía del hombro izquierdo, sobre el que se dejaba caer hacia adelante, se le hacía descender por la espalda, pasar por entre las piernas, subir por el vientre para ser sujeto a la cintura por un cíngulo. El faldón sobrante se enrollaba después en torno a las caderas, para acabar anudando el pico terminal con el primero que se había dejado colgando sobre el hombro izquierdo.

Durante las dínastías XVIII y XIX (1580-1250 a.C.) se impuso la llamada «amalafa real» (figura 13), así llamada por su similitud con una prenda de corte semejante adoptada más tarde por los árabes. Fue una especie de túnica de lino muy transparente cuyo uso se generalizó a partir de la época de Amenofis IV (1379-1362 a.C.), gustoso de vestir ropajes de corte femenino o de mitigar, tal vez de acuerdo con sus criterios religiosos o estéticos, las diferencias entre ambos sexos. Se trataba de un largo y suave paño de forma rectangular y de textura parecido a la muselina, sujeto, a la postre, tras una compleja disposición de vueltas en torno al cuerpo por un único nudo sobre el pecho. Se comenzaba situando un ángulo del rectángulo sobre el hombro izquierdo, se dejaba resbalar el tejido hasta la cintura y se arrollaba alrededor del talle, fijándolo por medio de un cintuión, adornado en su parte delantera con cintas multicolores que, más tarde se transparentarían bajo la segunda capa de esta prenda. Se subía la tela hasta la axila izquierda y desplegada se procedía a envolver el cuerpo por encima del pecho y cubrir el hombro derecho con el último extremo que se anudaba, finalmente, con el cabo inicial dejado sobre el hombro izquierdo. Su uso se generalizó entre los nobles y altos dignatarios (figura 14).

Como complemento de la vestidura real hay que añadir las tiaras, tocados y cetros que eran de uso exclusivo de la realeza. Las tiaras o coronas faraónicas fueron principalmente dos: la roja, "deshert», adornada con el cayado, "hega", símbolo de la realeza del Bajo Egipto, y la blanca, «hedyet», con el «uraeus» o cobra sagrada que simbolizaba, a su vez, la realeza del Alto Egipto. Con la fusión de «las dos tierras», se fusionaron también ambas coronas dando lugar a la doble tiara, el «pschent» que lucirían los faraones a partir de la unificación de los dos Egiptos llevada a cabo por Narmer (Menes) hacia el 3000 a.C., en ceremonias en que se hacía preciso testimoniar dicha unión (figura 15). 

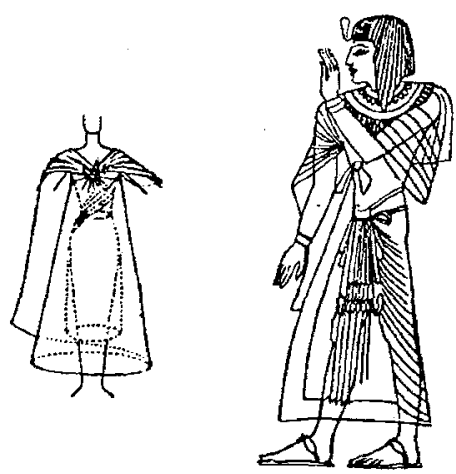

Figura 13. El manto o «amalafa real", prenda cuyo uso se generalizó a partir de las dinastías XVIII y XIX (1580-1250 a.C.).
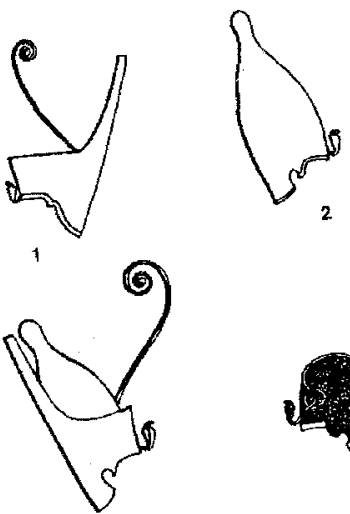

3

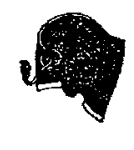

4

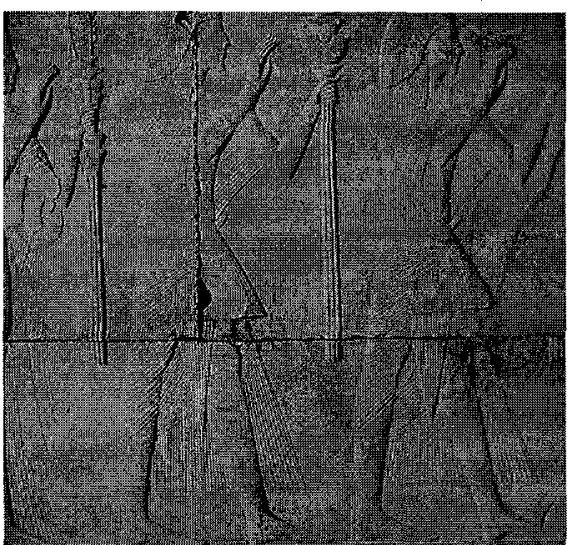

Figura 14. Procesión de oficiantes del templo funerario de Ramses I, construido en Tebas por su hijo Seti I (1318-1304 a.C.), vistiendo amplios mantos transparentes ("amalafas") y llevando en sus manos sistros y cetros. Museo Metropolitano de Nueva York.

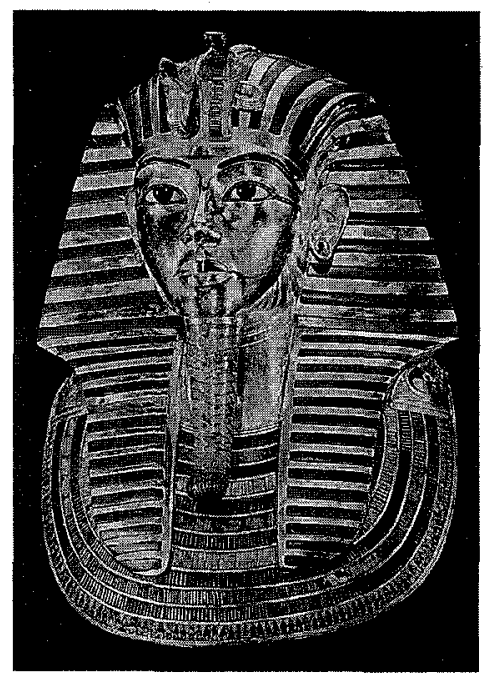

Figura 15. Coronas o tiaras faraónicas: 1) corona roja, «deshert», adornada con el cayado, "hega"; 2) la blanca, "hedyet, con el distintivo del «uraeus» o cobra sagrada; 3) la doble corona, "pschent", símbolo de la unidad de los dos Egiptos; 4) el "kephresh", casco militar de parada.
Figura 16. Máscara de oro de Tutankhamon (1361-1352 a.C.) luciendo el "klaft» $o$ «nemes"; sobre la frente campean las efigies de la diosa cobra "Udjet", del Bajo Egipto y la diosa buitre "Nekabit», del Alto Egipto. Museo de El Cairo. 
Tocado faraónico fue también el «klaft» o «nemes», al parecer un cuadrado de tejido rígido o engomado, decorado con franjas paralelas doradas y azules y que, sujeto en la nuca, por detrás de las orejas, enmarcaba al rostro con dos simétricos triángulos. Sobre la frente campeaban las efigies de la diosa cobra «Uadjet» y la diosa buitre «Nekabit» (figura 16).

El tocado de carácter militar y de parada fue el «khepresh", un casco de cuero azul cuyo uso se generalizó a partir de la segunda fase del Imperio tebano y, sobre todo, desde la época de Akhenatón que gustó de hacerse representar con él en numerosas ocasiones. Se le ha supuesto una creación inspirada en modelos asiáticos. Se conocen dos variantes del casco militar según vemos en la figura 17. El primero era de carácter ceremonial y el segundo de combate.

Por último, hay que recordar el uso de las pelucas que también variaron de formas y estilos en cada época. A causa del calor y como medida de limpieza para evitar parásitos capilares, los egipcios, hombres y mujeres, solian afeitarse la cabeza. Esta práctica se generalizó a partir del Imperio Nuevo, momento en el cual la fabricación de las pelucas alcanzó su máxima producción y variedad. El cuero cabelludo desnudo precisaba de una protección contra los rayos solares que entre la población artesanal y obrera, sobre todo en el sector masculino, se solucionó con un gorro de fieltro negro, tocado que también en la intimidad solían llevar los personajes acomodados. Sin embargo, entre las clases altas se generalizó el uso de pelucas de lino negro, compuestas de mechones retorcidos en espiral o muy finamente trenzados. Las pelucas masculinas del Imperio Antiguo (2890-2475 a.C.) eran de mechones cortos, dispuestos los unos sobre los otros de forma circular en torno a una especie de coronilla situada en la parte superior de las mismas. También las había con raya en medio, de mechones largos y lisos formando dos aladares, a veces explayados en su parte delantera o cubriendo las orejas, llegando o pasando la línea de los hombros. Durante el Imperio Medio y Nuevo las pelucas fueron largas y lisas, escotadas en los hombros. En la segunda etapa de este período alcanzaron formas complejas y variadas, muy semejantes a las femeninas (figuras 18,19 y 20 ).

Símbolo de divinidad y soberanía fueron los cetros usados por dioses y faraones: el «hega» o cayado; el flagelo o látigo, «nekheh»; el cetro, «uas», rematado en su parte superior por una estilizada y supuesta cabeza de cánido y terminada en doble punta ahorquillada; y la maza, «hedi», de carácter militar y de parada, ya que con ella se aplastaban las cabezas de los ene- 


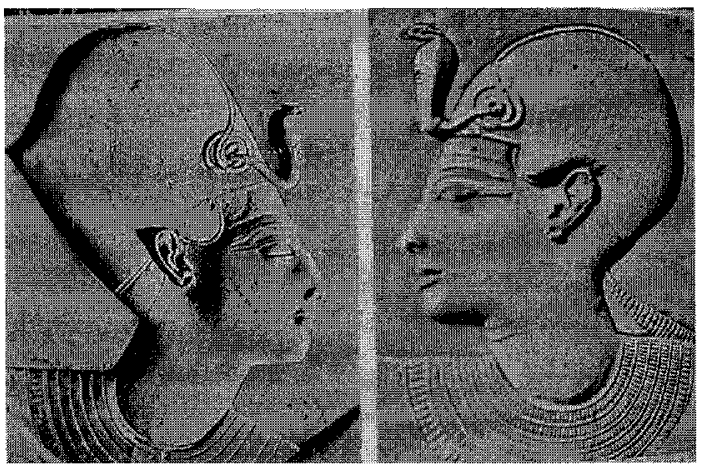

Figura 17. El Faraón Setil (1318-1304 a.C.) con casco de parada y de combate, relieves de su templo funerario en Abydos.

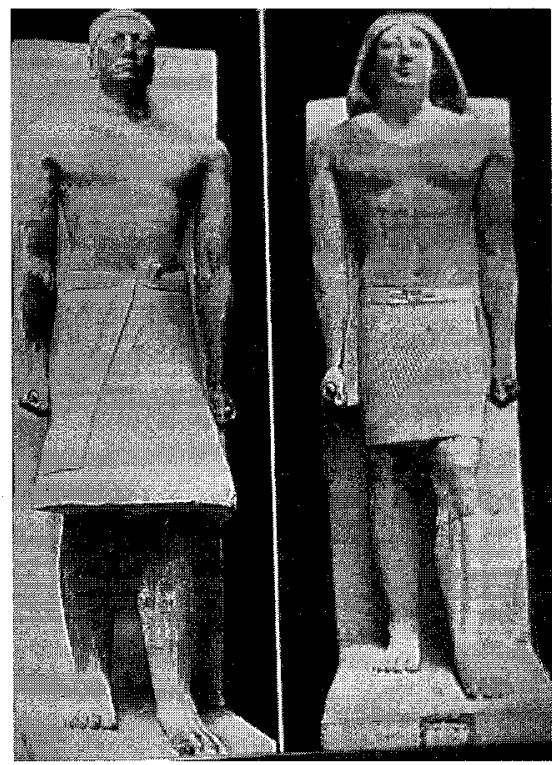

Figura 19. Retratos funerarios de Ranefer, gran sacerdote del templo de Ptah, en Menfis, durante la dinastía IV (2590-2463 a.C.). En la efigie de la izquierda aparece con pelo corto o gorro de fieltro, $y$ viste manto arrollado en la cintura con faldón delantero engomado, dispuesto de forma triangular; en la segunda, la de la derecha, va tocado con una peluca de aladares explayados y viste la «shenti». Museo de El Cairo.

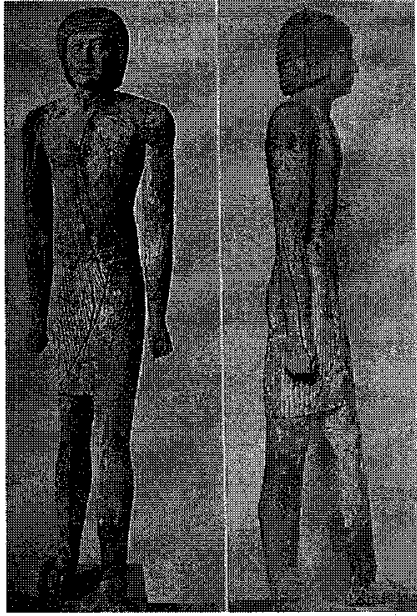

Figura 18. Estatua de madera, vista de frente $y$ de perfil, de Perhernefer, alto dignatario de la dinastía VI (2322-2130 a.C.), tocado con peluca corta $y$ vistiendo la "sentín. Museo de Berlín.

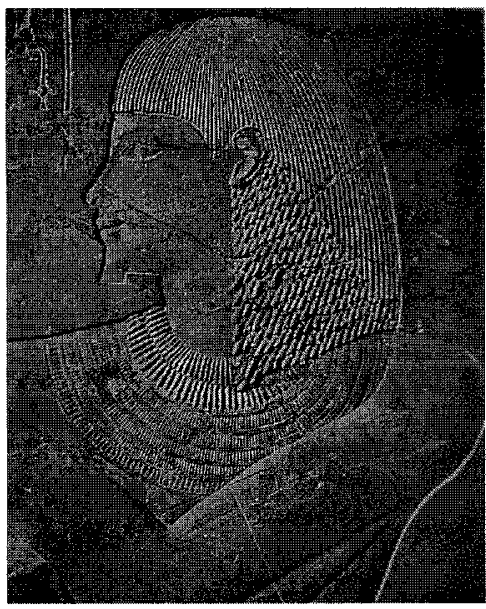

Figura 20. Retrato de Khaemet, ministro de Amenofis III (1417-1379 a.C.), luciendo una compleja peluca tratada a capas y con rizos dispuestos en dos diferentes direcciones, frecuente a partir de la dinastía XVIII (15541304 a.C.). Procede de su tumba en la necropolis tebana. Museo de Berlín. 
migos (figura 21). El «sekhem» 0 «aba» fue el cetro usado por príncipes y nobles de alta alcurnia y el «uadj», rematado en forma de media luna, o flor de loto abierta, fue atributo de las divinidades femeninas, en especial de Isis.

Atributo real fue también la barba postiza, usada, incluso, por la reina Hatsepsut, no dispuesta a renunciar al trono ni a su rango de legítimo faraón (figura 22). Tales barbas postizas debieron de usarse desde épocas muy remotas como atestiguan algunas estatuillas masculinas de época predinástica procedentes del Alto Egipto, que visten un simple estuche fálico y llevan barba postiza puntiaguda (figura 23).

Como señal de primogenitura divina o real, los legítimos herederos solian llevar una trenza lateral en el lado izquierdo de la cabeza que caía, formando un bucle sobre el hombro (figura 24). Este singular tocado se generalizó a partir del Imperio Nuevo y, más tarde, se convirtió en atributo propio de los llamados «divinos niños»: Horus, Khonsú, Harpócrates, etc.

Por último, cabe señalar que en Egipto sólo las clases superiores llevaron calzado. Tanto hombres como mujeres usaron sandalias muy simples, hechas de palmera, papiro o cuero, con la extremidad delantera levantada para proteger el dedo gordo (figura 7 ).

\section{EL TRAJE MILITAR}

En Egipto, el traje militar fue prácticamente inexistente hasta la época de Ramsés II (1304-1237 a.C.). No hay más que fijarse en las maquetas de soldados nubios, pertenecientes al Imperio Medio (2160-1580 a.C.), que se conservan en el Museo del Cairo (figura 25), para entender la indigencia de ropa con que se acudía a los campos de batalla. En ellas se pueden ver a infantes de tez oscura, pies y torsos desnudos, y cabezas cubiertas por pelucas muy cortas (probablemente acolchadas), que visten exclusivamente una exigua "shenti», con un faldellín polícromo sobrepuesto, distintivo probablemente de las tropas tributarias. En cualquier caso, son las armas que llevan en la mano, arcos y flechas, la formación del grupo y su decidida mirada al frente, los signos evidentes de su condición guerrera.

En el Imperio Medio también se observa que, en ocasiones, sobre la "shenti» de los arqueros o lanceros se sobreponía una especie de delantal de cuero o de piel de gacela que caía por detrás, hasta la altura de las corvas. 


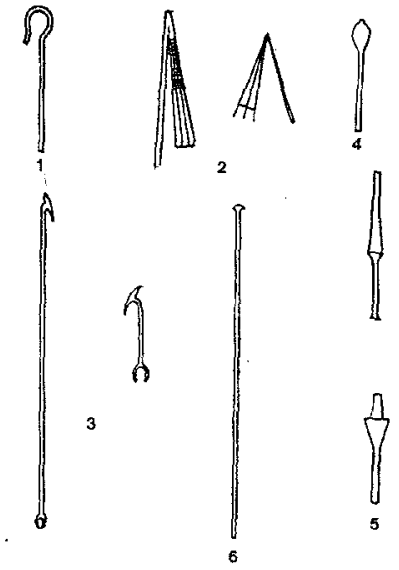

Figura 21. Cetros reales y principescos : 1) el cayado "hega»; 2) el flagelo o látigo "nekheh»; 3) el cetro "uas"; 4) la maza "hedj»; 5) el cetro «sekem» o "aba" usado por príncipes y nobles; 6) el cetro «uadj», atributo de lás divinidades femeninas.

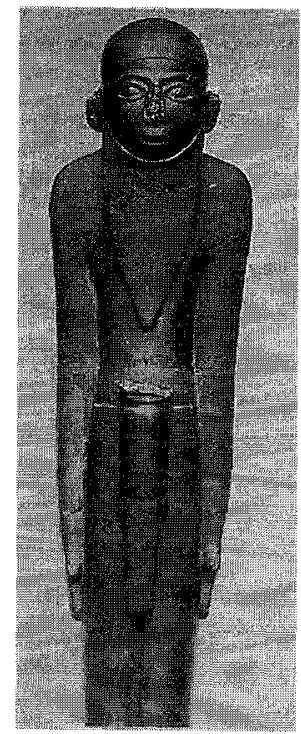

Figura 23. Estatua de basalto $(39 \mathrm{~cm}$. de altura), de procedencia desconocida, representando a un alto personaje $o$, tal vez, al dios Min de Koptos (Alto Egipto), con barba postiza y estuche fálico. Hacia el 3000 a.C.

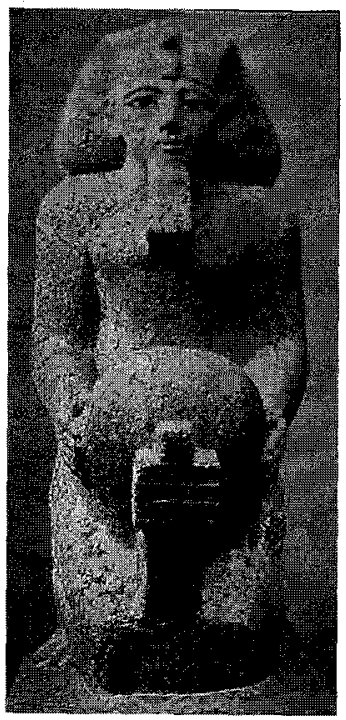

Figura 22. Retrato de la reina Hatsepsut (1503-1482 a.C.), de granito gris, con el «klaft» y la barba postiza. Museo Metropolitano de Nueva York.

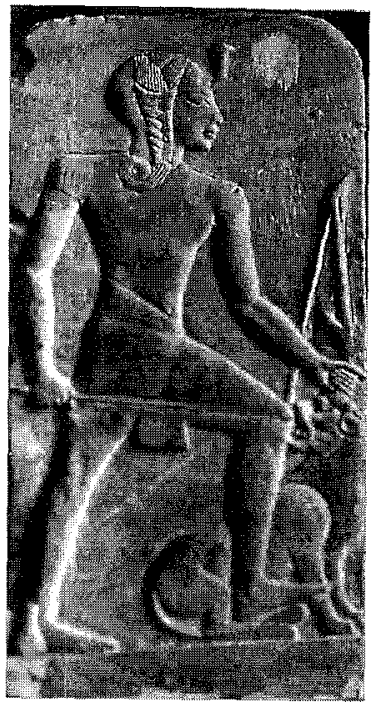

Figura 24. Ramsés II (1304-1237 a.C.), con tocado de príncipe heredero, acompañado de un león. Museo del Louvre, París. 


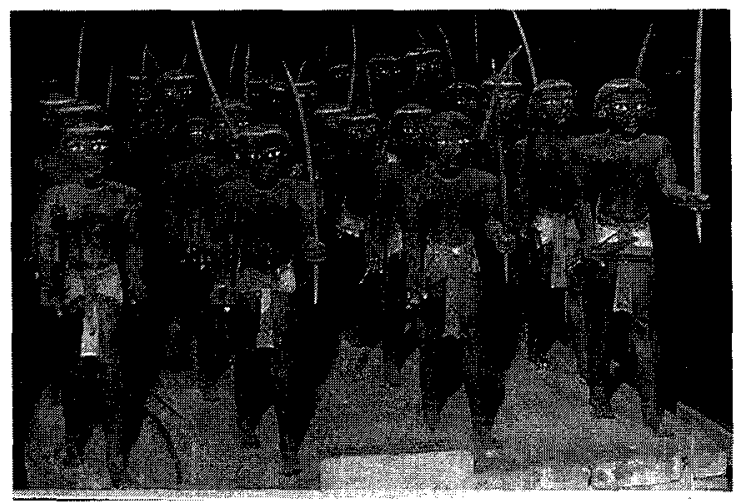

Figura 25. Soldados nubios del Imperio Medio, dinastía $X$ (hacia 2040 a.C.). Madera pintada. Procede de la tumba del faraón Mesethi. Museo de El Cairo.

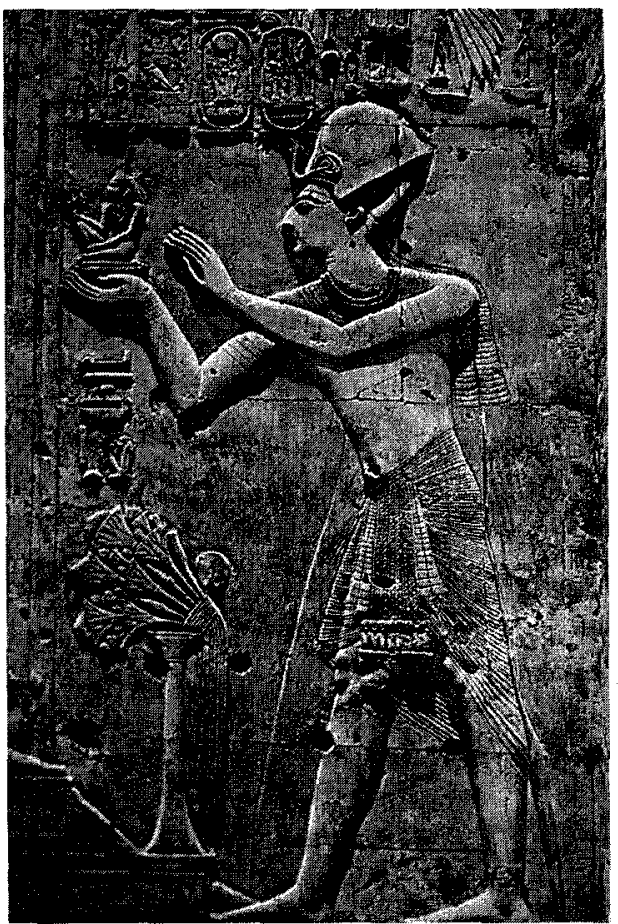

Figura 27. Seti I (1318-1304 a.C.) ofreciendo la estatua de la diosa Maat, con indumentaria militar. Relieve de su templo en Abydos.

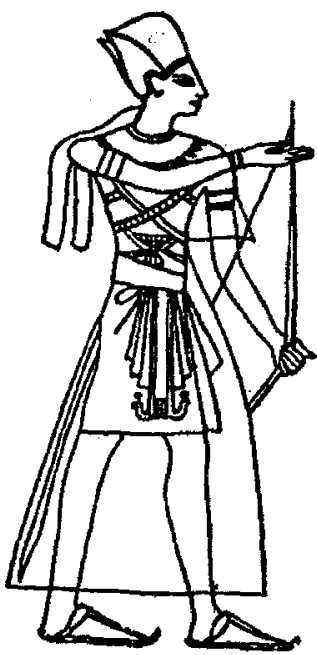

Figura 26. Indumentaria militar a partir de Seti l (1318-1304 a.C.) y Ramsés II (1304-1237 a.C.).

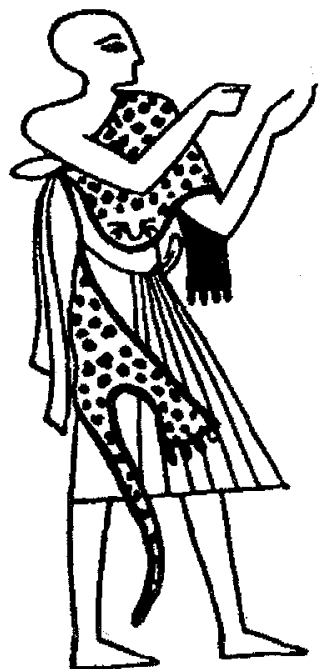

Figura 28. Indumentaria sacerdotal, con la piel de pantera, atributo de su ministerio. 
A la vista de estos ejemplos, es de suponer que tal era el aspecto que ofrecían las tropas egipcias hasta que Ramsés II procedió a instituir un ejército regular y profesionalizado, totalmente necesario para poder enfrentarse a los hititas y libios. Estos últimos, curiosamente, tras ser combatidos por Ramsés II y Ramsés III, Ilegarían a constituir la clase militar dominante que ascendería al trono a su gran jefe Shoshenk (ca.945-924 a.C.) que inauguró la XX dinastía, la llamada libia. La reforma de Ramsés II fue válida hasta la época de los Ptolomeos quienes impusieron a los ejércitos egipcios los sistemas de armamento y combate griegos.

A partir de la reforma ramesida, los oficiales de rango superior vistieron la «calasiris" sobre la «shenti» y sobre ella una coraza de lino o de cuero. Gozaron de especiales privilegios los oficiales pertenecientes a las órdenes de honor: "del León», "del Collar», "de la Mosca», "Medalla al Valor», a quienes se les permitía lucir armas honoríficas o de parada, sobre todo en los actos públicos. La llamada «guardia extranjera» de Ramsés II también usaba coraza, un tocado con cuernos, escudo y larga espada de hoja triangular.

Los príncipes reales solían lucir un coselete o coraza de lino bordada ricamente con motivos alusivos a la caza o a la guerra, con hilos de oro, plata y algodón. El faraón se cubría el torso con un chal entrecruzado, de unos $4 \mathrm{~m}$. de largo, que le servía de protección interna, la "shenthi», la "calasiris" y sobre ella la coraza de cuero en el campo de batalla. Su cabeza se cubría con el «kepresh», el casco azul, también de cuero (figuras 26 y 27$)$.

\section{LAS VESTIDURAS SACERDOTALES}

En un principio los sacerdotes que sabido es llevaban la cabeza y el cuerpo totalmente rasurados como símbolo de pureza vistieron la «shenti» y sobre ella el manto arrollado al talle. Posteriormente pasó a enrollarse bajo las axilas confiriendo a los sacerdotes su aspecto más conocido. Sobre el pecho llevaban una especie de chal y, en los momentos de los oficios sagrados, se revestían con una piel de pantera, atributo de su ministerio. Sobre dicha piel, colocada de forma terciada, solían lucir un collar trapezoidal y calado, símbolo de la jerarquía sacerdotal, el "sah" que a veces se superponía sobre otro no menos importante, el «usekh» (figuras 28 y 29 ). 


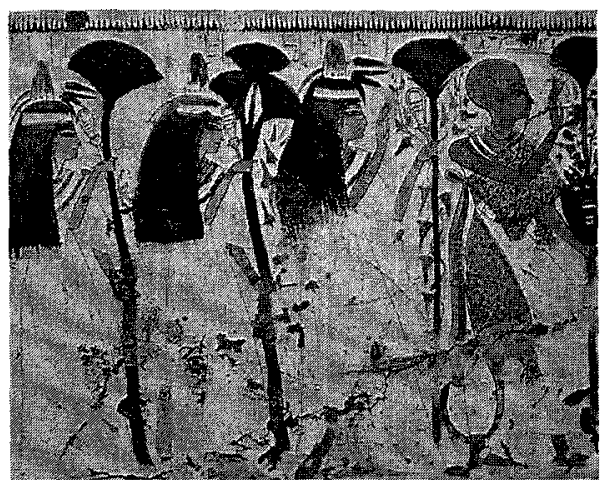

Figura 29. Cortejo funerario de muchachas vestidas con ligeras y transparentes túnicas, Jargas pelucas rematadas con cuentas de colores $y$ ceñidas por cintas y flores de loto, con el pomo de crema compacta y perfumada. Llevan sistros y flores de loto en sus manos y marchan tras la Figura de un sacerdote de cabeza rasurada que viste la piel de pantera. Tumba de Userhart. Imperio Nuevo. Necrópolis tebana.
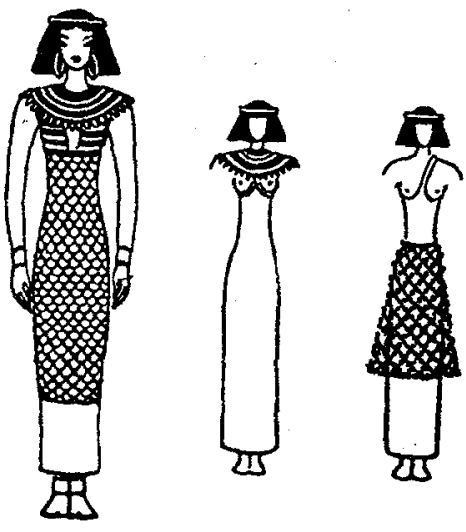

Figura 30. Indumentaria femenina del Imperio Antiguo.

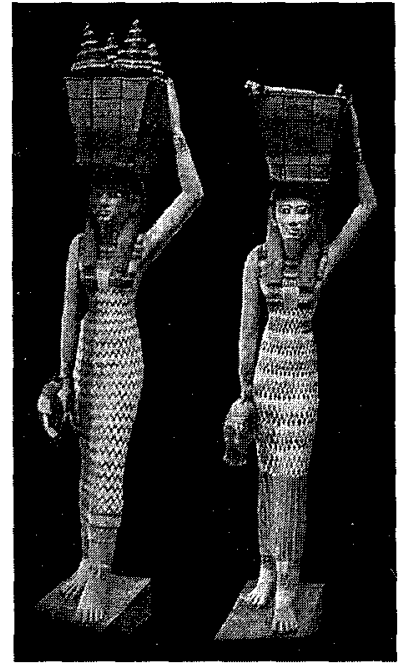

Figura 31. Figuritas de arcilla policromadas de sirvientas que portan panes y patos para el consumo del difunto. Visten túnicas estrechas ceñidas al cuerpo, recubiertas por redecillas hechas con cuentas de materiales polícromos. Imperio Medio (2168-1580 a.C.). Museo Metropolitano de Nueva York.

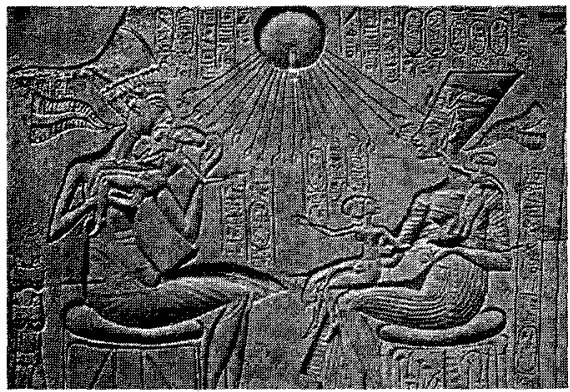

Figura 32. Relieve de El Amarna. El faraón Akhenaton (1379-1362 a.C.) y la reina Nefertiti con sus hijas, vivificados por el disco solar Aton, vistiendo las vaporosas y plisadas vestiduras propias de la época. Museo de Berlín. 


\section{EL VESTIDO FEMENINO}

El vestido femenino durante los Imperio Antiguo y Medio fue muy simple. Se reducía a una especie de túnica de lino blanco o color crudo, muy ceñida al cuerpo, abierta con un escote de pico para permitir el paso de la cabeza, o sujeta por un tirante al bies o dos tirantes que cubrían en parte los senos y los hombros. Las reinas y princesas de estos períodos solían vestir túnicas de color azafrán o rojo, ya que dichos tonos por el alto coste de su teñido, fueron en la Antigüedad signo evidente de poder y alcurnia.

A pesar de la sencillez de corte de esta prenda básica del vestido femenino, los realces se los proporcionaban los bordados y adornos que llevaban las túnicas de las damas nobles o los revestimientos de redecillas hechas de diminutas cuentas multicolores, de quita y pon, que usaban como complemento las mujeres del pueblo. A esto hay que añadir los collares, pulseras en muñecas, brazos y tobillos, pelucas, coronas etc. (figuras 11,30 y 31 ).

En el Imperio Nuevo, por influencia de los gustos asiáticos, muchos de los cuales importaron las princesas extranjeras que pasaron a vivir en los harenes del faraón, se impusieron los tejidos suaves y vaporosos, finamente plisados, al igual que había sucedido con los vestidos masculinos. Entonces, sobre la túnica se empezó a llevar una especie de blusa de anchas mangas plisadas, imitando las alas de Isis replegadas y cruzadas alrededor del cuerpo. Es también en el entorno de El Amarna, en la corte de Akhenatón y Nefertiti donde se produjeron tales innovaciones, continuadas en la época de Ramsés II y de la mano de su bella esposa, Nefertari (figuras 32 y 33). Los mantos adquirieron largas proporciones de modo que tras enrollarse al cuerpo varias veces, se atasen sobre el pecho con un nudo.

De entre todos estos mantos es de destacar el conocido como «la amalafa de Isis», una prenda de $3 \mathrm{~m}$. cle longitud y $1,30 \mathrm{~m}$. de ancho. Para su colocación se doblaba por la mitad de su longitud, colocándose en ese punto sobre el pecho; después las dos partes iguales del manto se pasaban por debajo de las axilas, se cruzaban en la espalda, se cubrían los hombros y sus extremos superiores se anudaban sobre el pecho originando el llamado "nudo de Isis» que luciría siempre esta diosa en sus numerosas representaciones tanto en el mundo helenístico como en el romano (figura 34).

Este largo manto, colocado según el llamado «plegado etíope», se disponía de la siguiente forma: uno de los extremos se dejaba colgar sobre el 


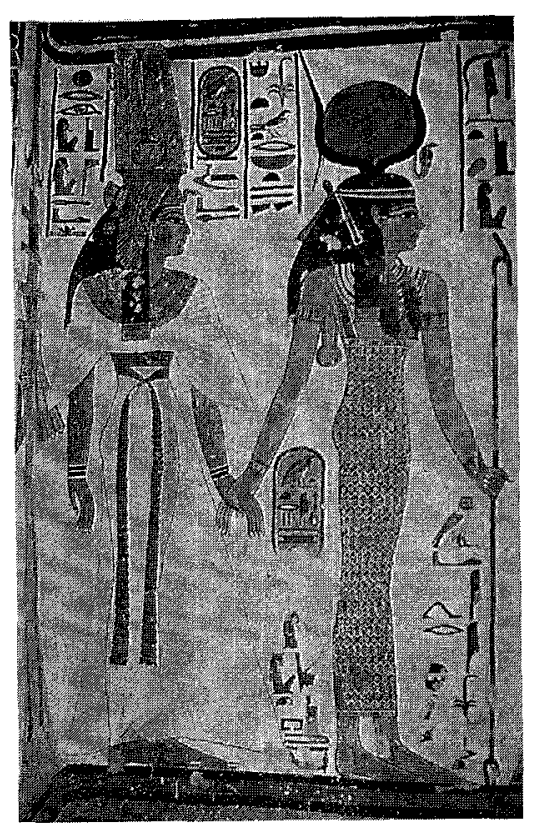

Figura 33. Isis con el tocado de Hathor presentando a la reina Nefertari, esposa de Ramses I/ (1304-1237 a.C.), ante Osiris. La diosa viste la túnica arcaizante, con tirantes, ceñida al cuerpo, y Nefertari la vaporosa $y$ transparente de su época, de amplias mangas plisadas. Tumba de Nefertari. Tebas.

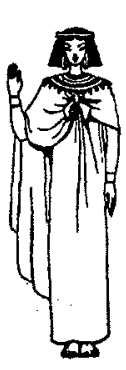

1

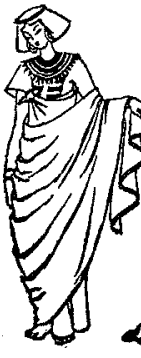

2

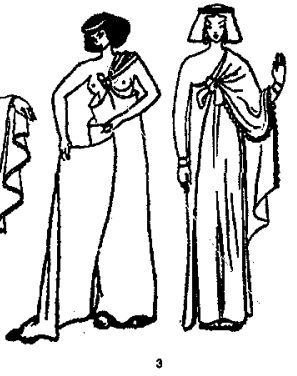

3
Figura 35. Disposición de los mantos (o "amalafas") femeninos en el Imperio Nuevo: amalafa de Isis, amalafa con plegado etiope $y$ amalafa con plegado doblado.

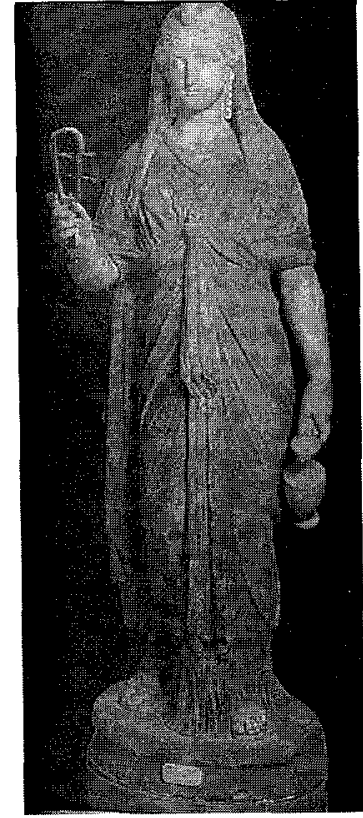

Figura 34. Estatua de la diosa lsis, del siglo /l d.C. Museo de Nápoles.

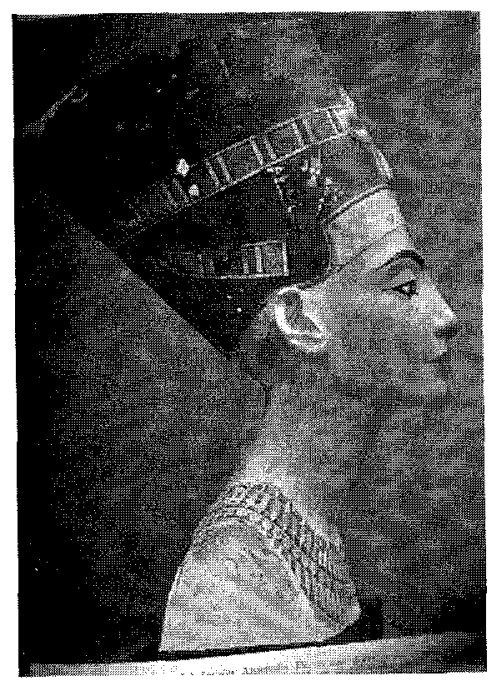

Figura 36. Busto de la reina Nefertiti, esposa del faraón Akhenaton (1379-1362 a.C.). Museo de Berlín. 
hombro derecho, el resto se enrollaba alrededor del cuerpo a la altura de las axilas. Después, la punta superior del faldón se anuda con el colgante del hombro derecho y el resto se echaba sobre el brazo izquierdo.

Otra forma de disposición de esta prenda era la que se denomina «de plegado doblado». Consistía en anudar uno de sus extremos al borde superior de su centro, entre los dos pechos. Se enrollaba después al cuerpo, se le hacía llegar hasta la mitad delantera del mismo, se le hacía un doblez y el faldón restante se echaba hacia atrás, de forma que apareciera cubriendo el hombro izquierdo. Su extremo superior se anudaba con el borde del doblez antes marcado, en el centro del pecho (figura 35).

Después de lo expuesto, queda claro que era el arte en la disposición de las prendas femeninas lo que las confería su encanto y variedad, ya que la mayoría eran paños de lino, más o menos transparentes, más o menos largos, pero siempre de forma rectangular, tal y como se tejían en los telares.

Las pelucas femeninas fueron, asimismo, de formas muy variadas. En el Imperio Antiguo fueron de aladares lisos y cortos. Por lo general no pasaban de la línea de los hombros. En el Imperio Medio alargaron sus medidas, llegando a ser, en algunos casos. ampulosas y barrocas. En el Imperio Nuevo se impusieron unos tipos de pelucas muy decorativas y largas, rematadas por pasamanerías y cuentas polícromas. Se ceñían con cintas de colores, adornadas con flores de loto naturales y, en ocasiones, se coronaban con unos conos de grasa perfumada que, deslizándose sobre la piel, le servía de aceite protector para evitar su sequedad (figura 29). Algunos de los restos de las vaporosas túnicas que lucieron las damas tebanas aún conservan las manchas de las esencias con que se hacian tan singulares cremas compactas.

Como complementos de adorno estaban las joyas: brazaletes; sortijas, collares con pinjantes, cinturones, coronas etc. La mayoría eran de oro, utilizándose como pedrería el lapislázuli, la amatista, el granate, el cristal de roca, la obsidiana, el ámbar amarillo y una gama muy numerosa de cristales coloreados.

Las reinas llevaron coronas y tocados especiales. Por su originalidad merece ser destacado el del busto de Nefertiti, hallado en 1912 por el profesor Ludwig Borchardt en la cámara de modelos del taller del escultor Tutmosis, en El Amarna y que se conserva en el Museo de Berlín. Esta estatua de caliza policromada, de unos $48 \mathrm{~cm}$. de altura, famosa en el 
mundo entero por su singular belleza, luce una corona azul de forma cónica y rematada de forma plana en su parte superior, única en el mundo egipcio (figura 36). Lo más frecuente en el Imperio Nuevo era que las reinas llevaran como tocado un buitre de oro, adaptado a la forma de la cabeza, cuyas alas explayadas encuadraban el rostro, mientras su cuello y cabeza se erguía sobre la frente (figuras 33 y 37 ).

Complemento esencial en el adorno de los egipcios y egipcias fue el uso de los productos cosméticos, con los cuales no sólo trataban de embellecer sus cuerpos y rostros, sino también de protegerlos. Se fabricaron a base de grasas vegetales y animales mezcladas con sustancias aromáticas y resinosas. Con el «kolh» (sulfato de antimonio) se marcaban el perfil de los ojos, y se intensificaba el negro de las pestañas con un polvo obtenido de la galena (sulfuro de plomo); los polvos para la sombra de ojos, azul o verde, se obtenían del antimonio, de la malaquita y de la azurita. Para su aplicación se mezclaban con grasa en una paleta de tocador, provista de una cazoleta central. Estas paletas hechas de pizarra, se encuentran ya en las tumbas del período predinástico, llegando en su dilatada evolución a alcanzar el grado de refinadas obras de arte a partir del Imperio Nuevo (figuras 38 y 39 ).

Para la obtención del rojo de labios y coloretes se utilizó el «fucus» un género de las algas pardas de las que obtenían yodo y sosa. Con la «hemma» (la alheña árabe, tinte obtenido de las hojas de lawsonia) fabricaban un producto de color anaranjado con el que se pintaban las uñas, palmas de las manos y plantas de los pies. Para tintarse el cuerpo también utilizaban el ocre (óxido de hierro hidratado) y el azafrán, con el que asimismo teñían telas y tejidos. Utilizaban la piedra pómez para la limpieza de los dientes y productos depilatorios para eliminar el bello superfluo.

La fabricación de los perfumes tuvo en Egipto un carácter semisecreto y casi religioso. Se hacian a base de mirra (gomorresina aromática), estoraque (bálsamo procedente de un árbol de la familia de las estiracáceas) y del benjui (sustancia resinosa obtenida por incisión en la corteza de un árbol del mismo nombre y semejante al estoraque), del incienso, resinas de trementina, betún de Judea y otros extractos vegetales de carácter aromático que se solían mezclar con vino de palma, pulpas de frutas, aceite de nardo, de sésamo o de almendras.

El consumo generalizado de todos estos productos generaron un activo comercio y una especialización en su elaboración. Por otro lado, impulsaron la fabricación de delicados objetos de tocador para contenerlos: pomos 


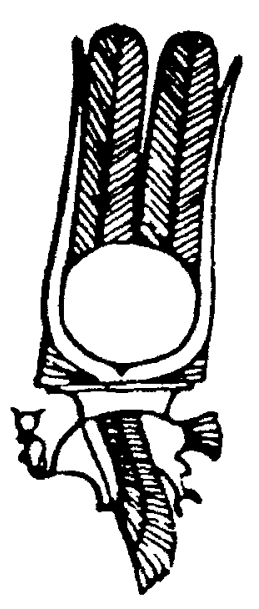

Figura 37. Tocado de diosas y reinas madres: corona de oro con la representación de la diosa Nekabit del Alto Egipto, y sobre ellas los atributos de Isis-Athor (la luna llena y los cuernos de la vaca sagrada) y las plumas enhiestas de Amón.

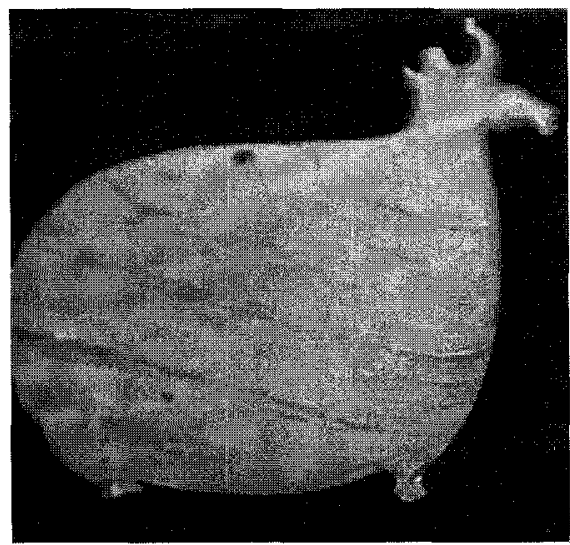

Figura 38. Paleta de pizarra predinástica (hacia 3200 a.C.). University College. Londres.

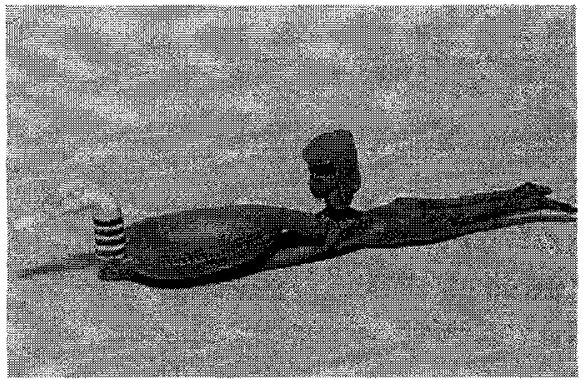

Figura 39. Cuchara de maquillaje del tipo llamado «la nadadora». Ébano y marfil., dinastía XVIII (1554-1304 a.C.). Museo del Louvre, París.

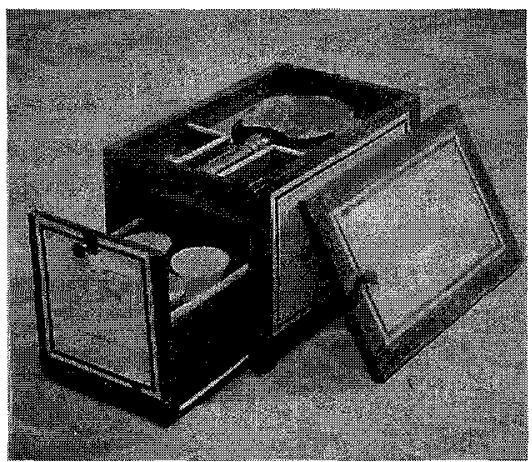

Figura 40. Cofre para guardar pomos de maquillaje y perfume, perteneciente a Renuni, mayordomo de Amenenhat III, dinastía XII (1991-1777 a.C). Metropolitan Museo de Nueva York. 
para los perfumes, cajitas para los ungüentos y cremas, espejos de bronce, paletas para las sombras de ojos y cofres, incluso, en los que se podían guardar todos los elementos que se precisaba para el cuidado corporal y el maquillaje (figura 40 ).

\section{BIBLIOGRAFIA}

Beaulieu, M.: El vestido Antiguo y Medieval, Barcelona, 1971.

CATÁlogo de la Exposición, Nofret la Bella. La mujer en el Antiguo Egipto. Fundación Caja de Pensiones. Madrid, 1986.

ElLIS, A.: The essence of beauty: a history of perfume and cosmetics. Londres, 1960.

Desroches Noblecourt, C.: La Femme aux Temps des Pharaons. Paris, 1989.

Harald Hansen, H.: Histoire du Costume. París, 1956.

HeuzEY, J.: "Les costumes des femmes de l' Egypte ancienne», en Gazette de Beaux-Arts, Vol. II, París, 1936.

LeloIf, M.: Diccionnaire du Costume, París, 1951.

Riefstalh, E.: Patterned Textiles in Pharaonic Egypt, Brooklyn-Museum, Nueva York, 1944.

SAISSET, P.: Histoire du costume, science vivante, París, 1959.

YoyotTE, J.: Los Tesoros de los Faraones. Génova, 1968. 